\title{
Academic Self-efficacy and its Relationship with Academic Variables among Kermanshah University of Medical Sciences Students: a Cross Sectional Study
}

\section{Mehdi Mirzaei-Alavijeh (PhD) ${ }^{1}$, Seyyed Nasrollah Hosseini $(\mathrm{PhD})^{2}$, Mohammad Ismail Motlagh (PhD) ${ }^{3}$, Farzad Jalilian (PhD $)^{4, *}$}

${ }^{1}$ Department of Public Health, School of Health, Kermanshah University of Medical Sciences, Kermanshah, Iran

${ }^{2}$ Ministry of Health and Medical Sciences, Tehran, Iran

${ }^{3}$ Department of Pediatrics, Faculty Medicine, Ahvaz Jundishapur University of Medical Sciences, Ahvaz, Iran

${ }^{4}$ Department of Public Health, School of Health, Kermanshah University of Medical Sciences, Kermanshah, Iran

* Corresponding Author: Farzad Jalilian, Department of Public Health, School of Health, Kermanshah University of Medical Sciences, Kermanshah, Iran.Email: fjalilian@yahoo.com

\begin{tabular}{|c|c|}
\hline \multirow{10}{*}{$\begin{array}{l}\text { Received: } 03 / 06 / 2017 \\
\text { Accepted: } 18 / 10 / 2017 \\
\text { How to Cite this Article: } \\
\text { Mirzaei-Alavijeh M, Hosseini } \\
\text { SN, Motlagh MI, Jalilian F. } \\
\text { Academic Self-efficacy and its } \\
\text { Relationship with Academic } \\
\text { Variables among Kermanshah } \\
\text { University of Medical Sciences } \\
\text { Students: a Cross Sectional } \\
\text { Study. Pajouhan Scientific } \\
\text { Journal. 2018; 16(2): 28-34. } \\
\text { DOI: } 10.21859 / \text { psj.16.2.28 }\end{array}$} & Abstract \\
\hline & \multirow{13}{*}{$\begin{array}{l}\text { Background and Objective: Academic self-efficacy defined as perception } \\
\text { of ability to do the tasks necessary to achieve the educational goals. } \\
\text { Students with higher academic self-efficacy have better educational } \\
\text { adaptability and more beneficial learning strategies. The aim of this study } \\
\text { was to determine the academic self-efficacy and its relationship with } \\
\text { academic variables among Kermanshah University of Medical Sciences } \\
\text { students. } \\
\text { Materials and Methods: This cross-sectional study conducted among } 370 \\
\text { of student Kermanshah University of medical sciences in } 2016 \text {. Students } \\
\text { selected in random simple sampling with probability proportional to size, } \\
\text { and data were collected by self-report with using academic self-efficacy of } \\
\text { McElroy questionnaire. Data were analyzed by SPSS-16 using Pearson } \\
\text { correlation, t-test and linear regression analyses. } \\
\text { Results: The age range of the students was } 18 \text { to } 29 \text { and the mean was } \\
22.99 \pm 3.35 \text { years. The mean of academic self-efficacy was } 53.10 \pm 7.40 \text {. } \\
\text { The student gained } 75.8 \% \text { of the maximum score of academic self-efficacy. } \\
\text { Higher age, married, not living in dormitory and educational level (MD } \\
\text { students) were significant predictors of higher level of academic self- } \\
\text { efficacy. } \\
\text { Conclusion: The planning an effective intervention to promote self- } \\
\text { academic, especially for undergraduate students are necessity. }\end{array}$} \\
\hline & \\
\hline & \\
\hline & \\
\hline & \\
\hline & \\
\hline & \\
\hline & \\
\hline & \\
\hline & \\
\hline & \\
\hline & \\
\hline & \\
\hline & $\begin{array}{l}\text { Keywords: Academic Achievement; Academic Adjustment; Academic } \\
\text { Self-efficacy; Educational Planning }\end{array}$ \\
\hline
\end{tabular}


dof: $10.21859 /$ psj. 16.2 .28

خودكار آمدى تحصيلى و ارتباط آن با متغيرهاى تحصيلى در دانشجويان دانشعاه علوم يزشكى كر مانشاه: مطالعه مقطعى

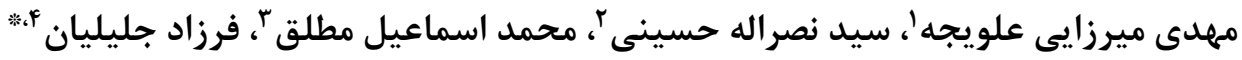
' استاديار، كروه بهداشت عمومى، دانشكده بهداشت، دانشگاه علوم يزشكى و خدمات بهداشتى درمانى كرمانشاه، كرمانشاه، ايران

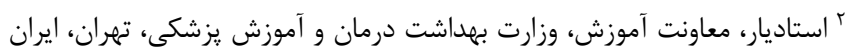

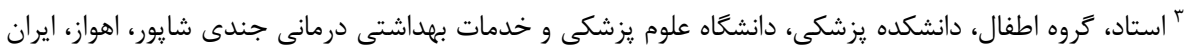

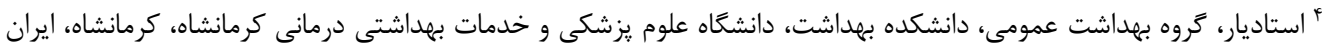
* نويسنده مسئول: فرزاد جليليان، كروه بهداشت عمومى، دانشكده بهداشت، دانشعاه علوم يزشكى و خدمات بهداشتى درمانى كرمانشاه، كرمانشاه، ايران. ايميل: f_jalilian@yahoo.com

جكيده

سابقه و هدف: خودكار آمدى تحصيلى به عنوان قابليت درك فرد از توانايىهاى خود در انجام وظايف لازم

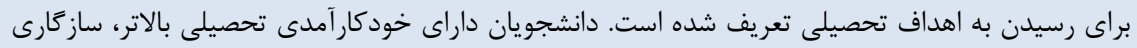

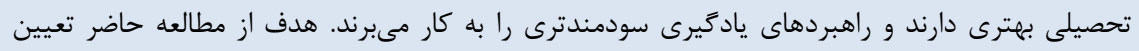

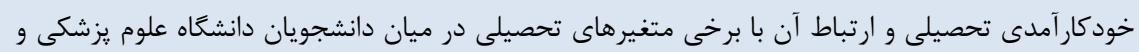

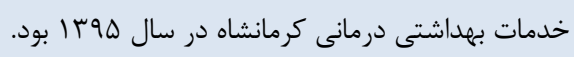

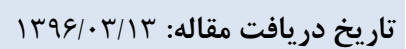

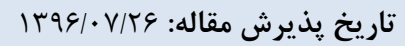
تمامى حقوق نشر براى دانشكاه علوم يزشكى همدان محفوظ است.

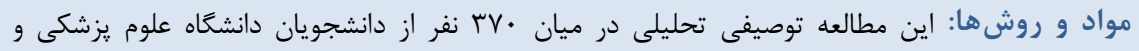

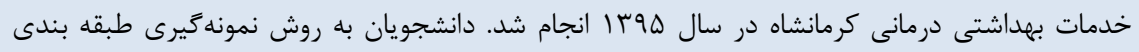

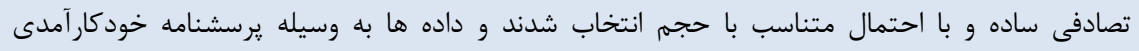

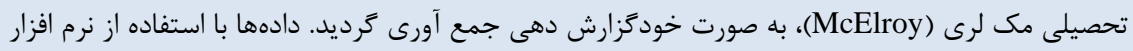

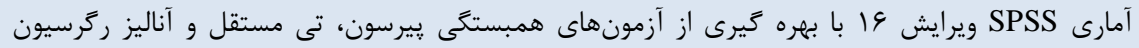
خطى مورد تجزيه و تحليل قرار كرفتند.

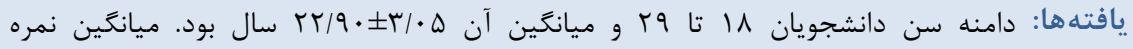

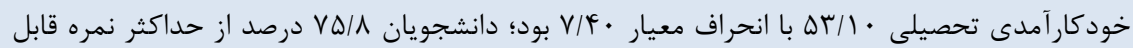

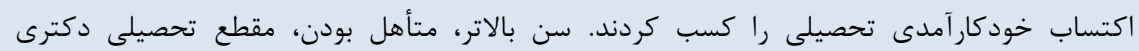

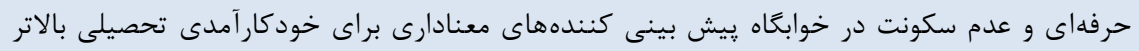
بودند. نتيجهَيرى: به نظر مىرسد برنامه ريزى مداخلات مؤثر در زمينه ارتقاى خودكارآمدى تحصيلى بخصوص

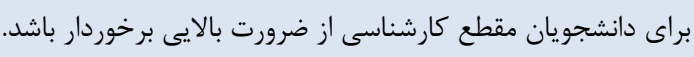

وازَٔان كليدى: برنامه ريزى آموزشى؛ پيشرفت تحصيلى؛ خودكارآمدى تحصيلى؛ سازگًارى تحصيلى

مقلdمه

بررسى هاى انجام شـده، در حسـدود rا ال درصـد از دانشـجويان

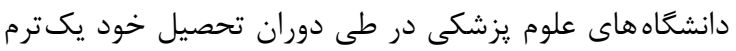

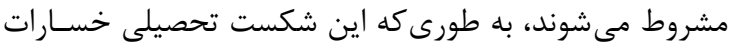

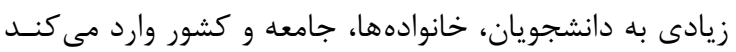

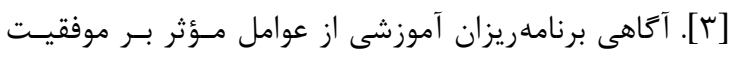

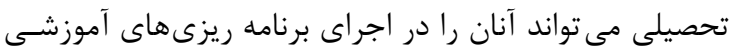

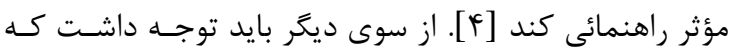

دانشـجويان يكـى از گــروههـاى بسـيار مهـهم در جامعــه

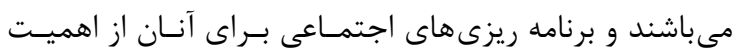

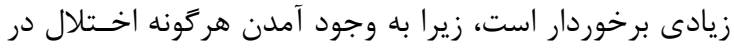

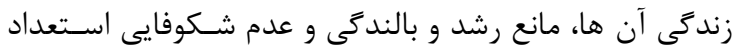

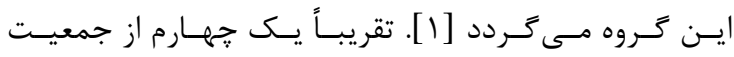
دانشجويى، در معرض خطر شكست تحصيلى و ديكر مشكلات

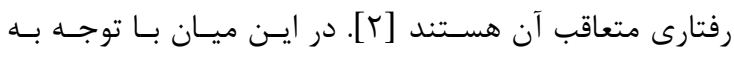


كه خودكار آمدى تحصيلى بالاترى دارند، سـاز كارى تحصـيلى

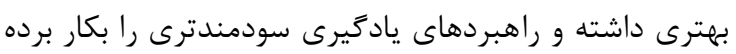

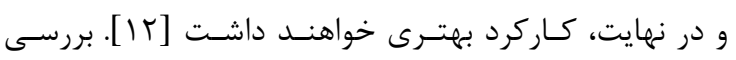

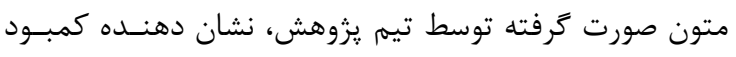

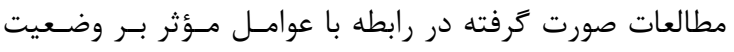

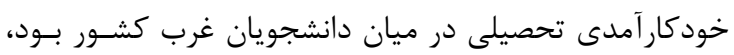

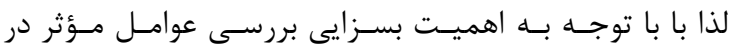

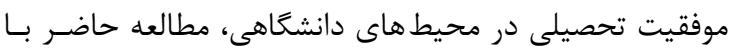

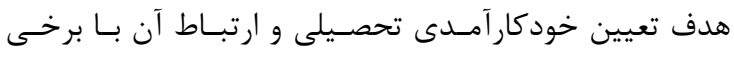

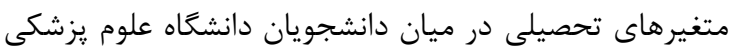
و خدمات بهداشتى درمانى كر مانشاه انجام شد.

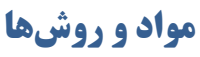

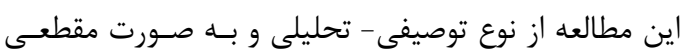

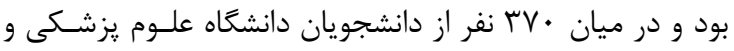

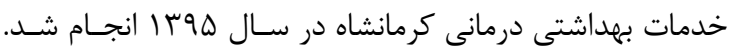
حجم نمونه مورد نياز در مطالعه حاضر با استفاده از فرمول زيــر

محاسبه شده است:

$n=\frac{\sigma^{2} * z_{1-\frac{\alpha}{2}}^{2}}{d^{2}}$

در فرمول فوق انحراف معيار متغير وابسته (خودكارآمدى آمدي

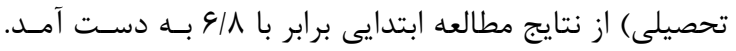

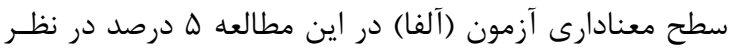

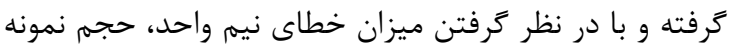

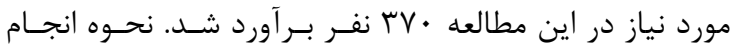

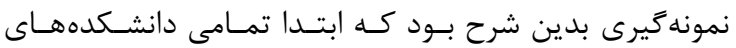

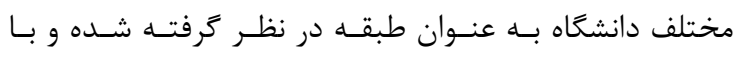

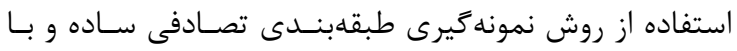
احتمال متناسب بـا حجـم (Proportional to Size) در هـ

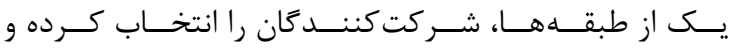

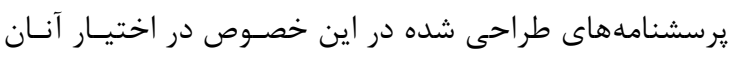

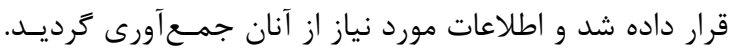

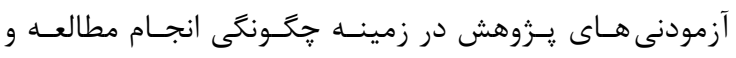

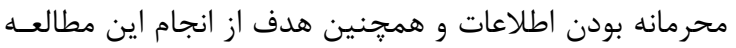

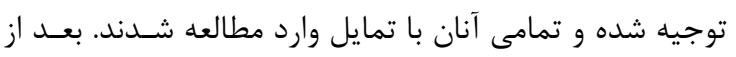

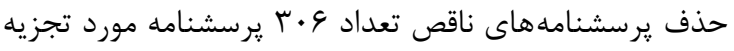

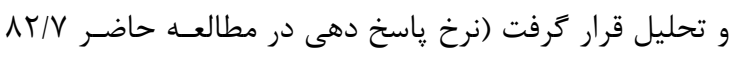

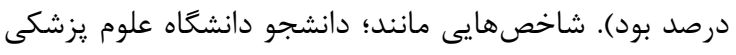

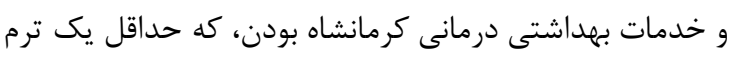

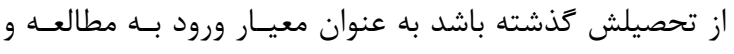

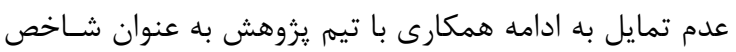
خروج از مطالعه در نظر ترفته شد.

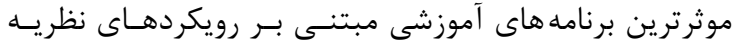

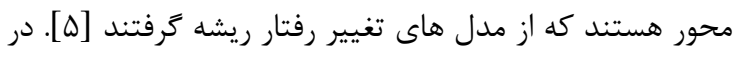

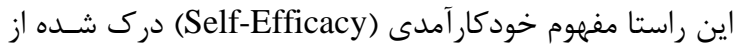

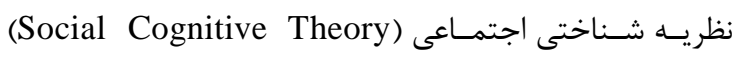

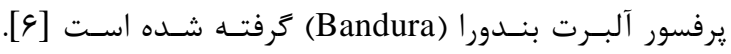

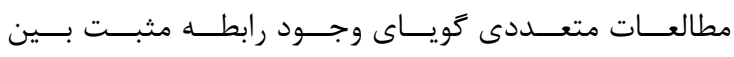

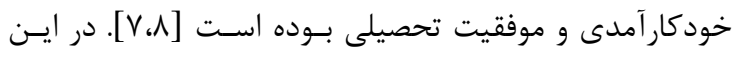

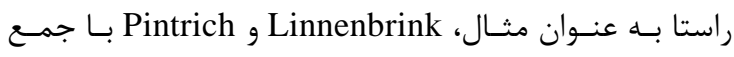

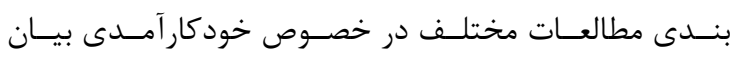

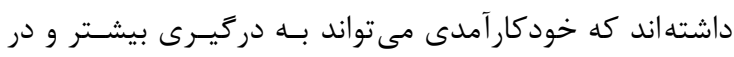

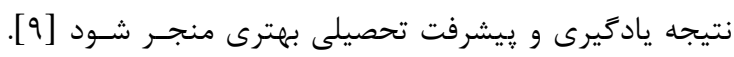

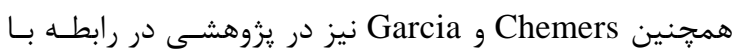

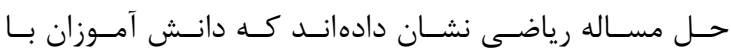

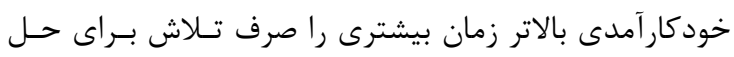

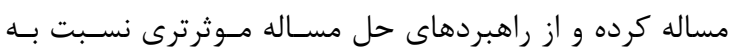

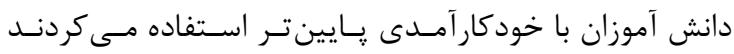

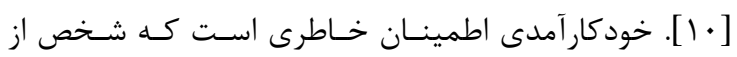

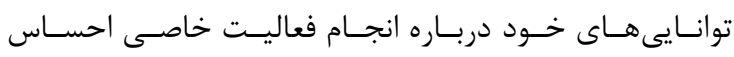

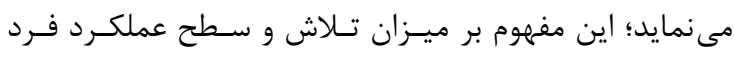

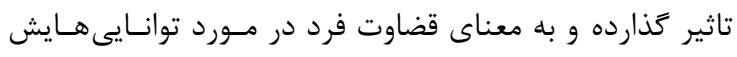

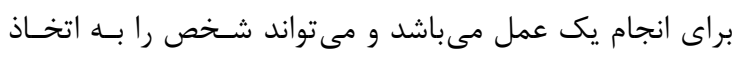

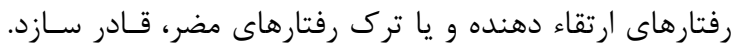

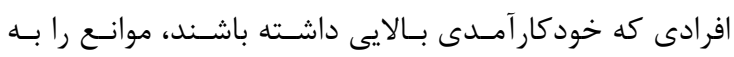

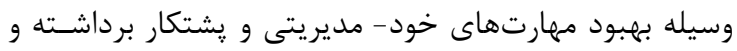

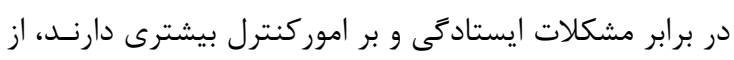

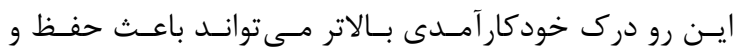

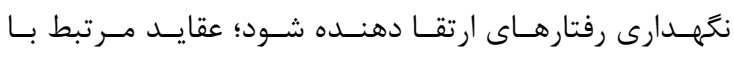

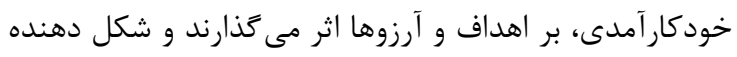

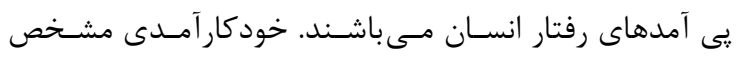

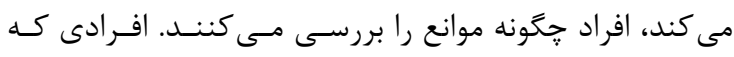

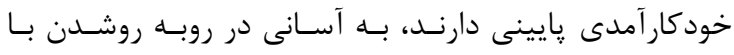

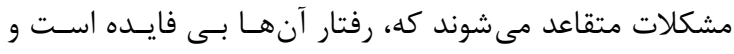

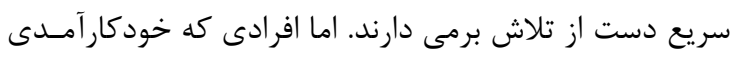

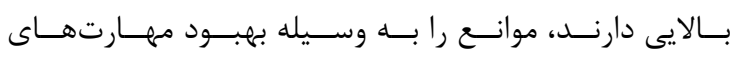

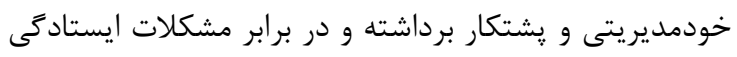

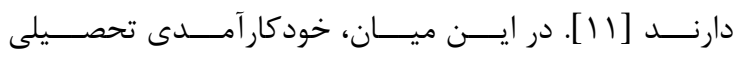

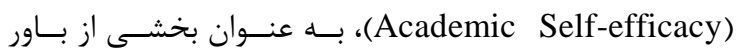

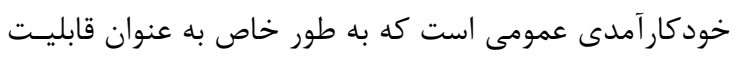

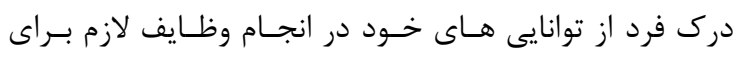

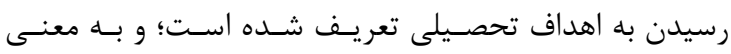

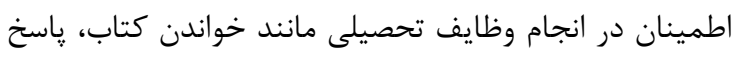

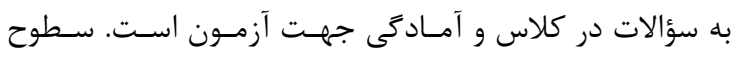

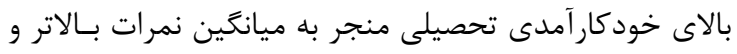

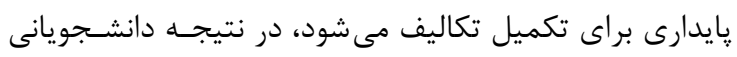


تجزيه و تحليل قرار ترفتند.

يافتهها

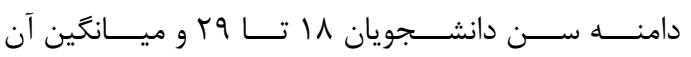

ه • /

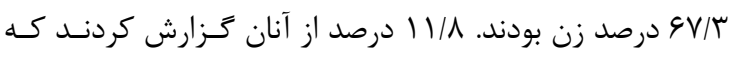

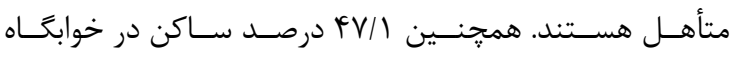

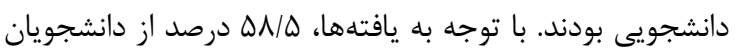

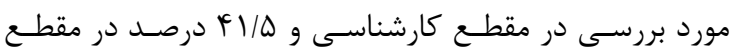

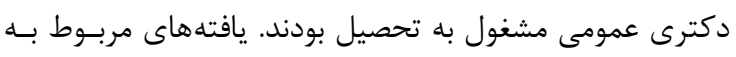

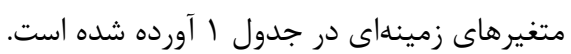

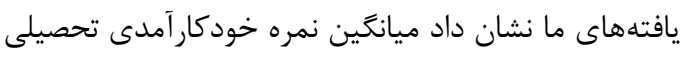

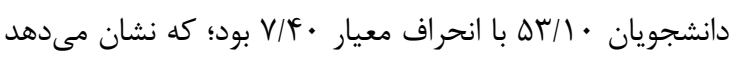

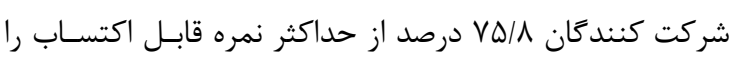

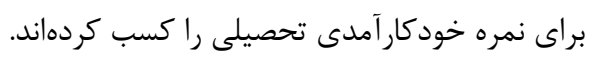

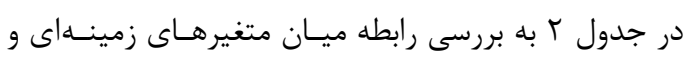

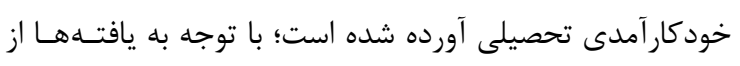

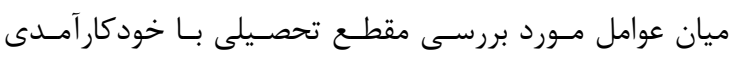

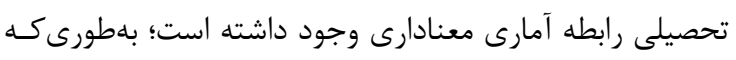

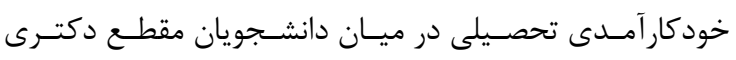

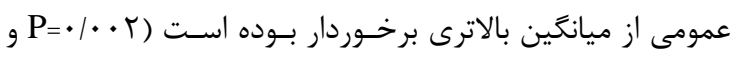

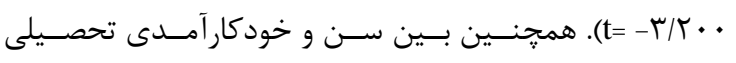

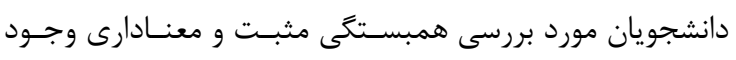
داست (• (r

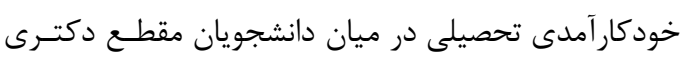

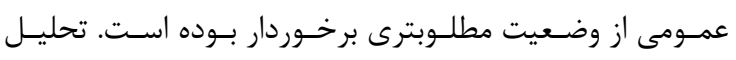

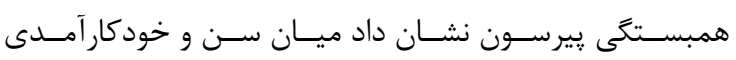
تحصيلى دانشجويان مورد بر رسى همبستخى مثبت و و معنـادارى

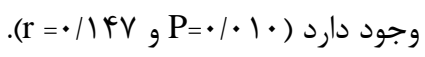

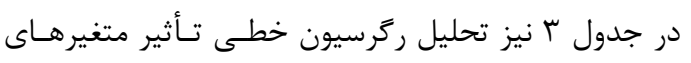

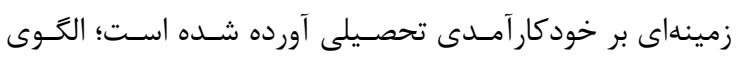

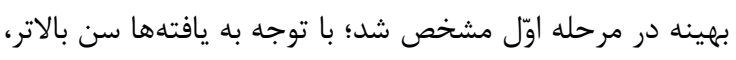

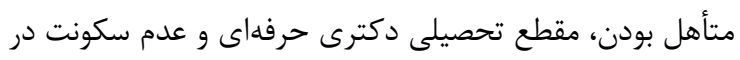

به منظور جمع آورى اطلاعات از دو يرسشــامه (اطلاعـات

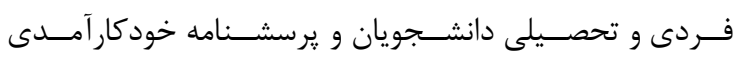

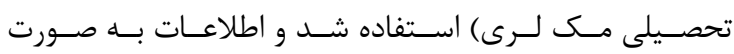

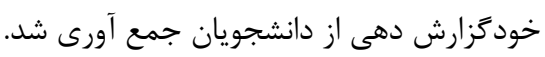

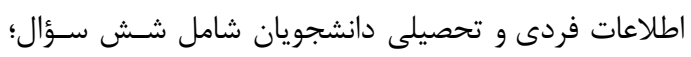

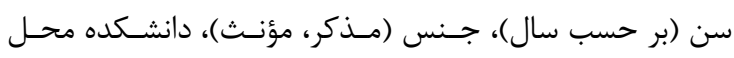

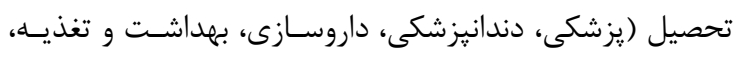

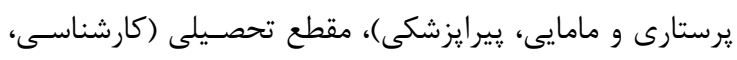

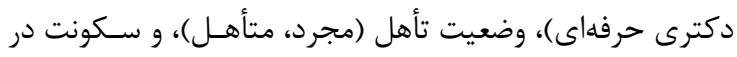

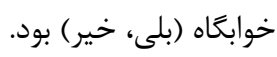

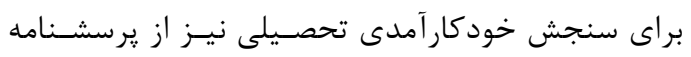

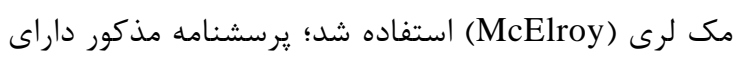

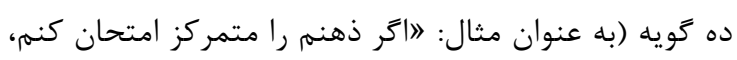

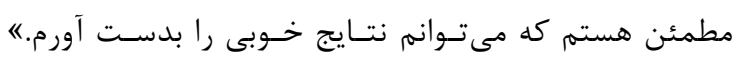

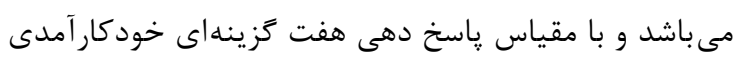

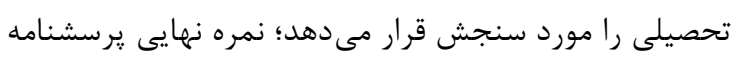

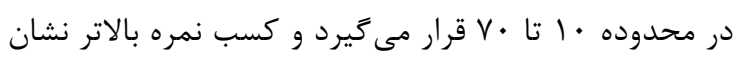

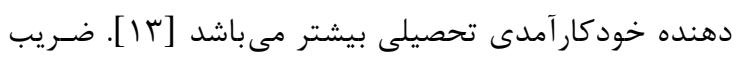

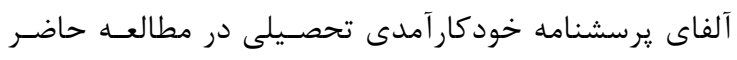

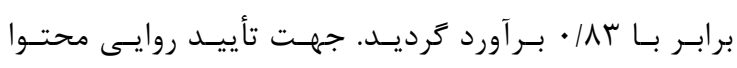

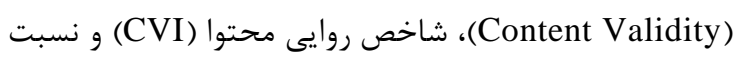

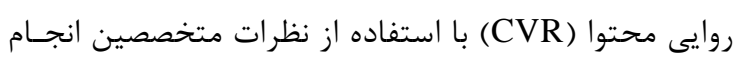

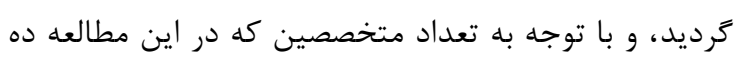

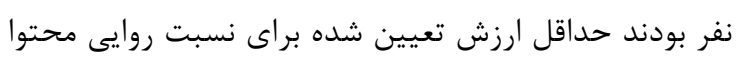

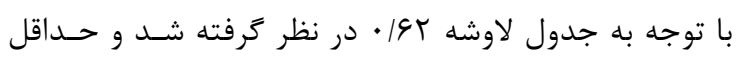

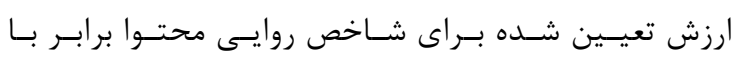

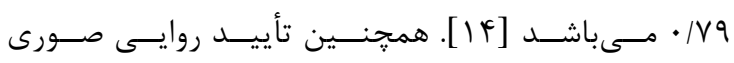

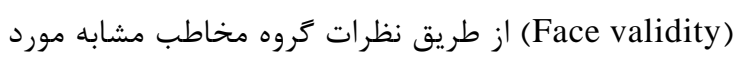

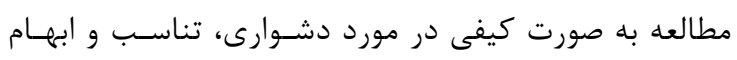

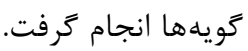

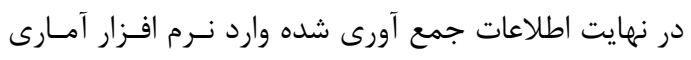
SPSS

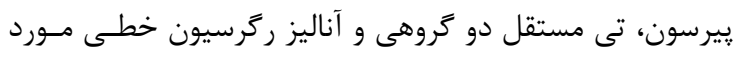

جدول ا: وضعيت متغيرهاى زمينهاى و تحصيلى دانشجويان

\begin{tabular}{|c|c|c|c|}
\hline درصد & تعداد & & متغير \\
\hline rT/V & $1 \cdots$ & مذكر & \multirow{2}{*}{ جنس } \\
\hline SV/T & $r \cdot 4$ & مؤنث & \\
\hline$\Delta r / q$ & 194 & خير & \multirow{2}{*}{ سكونت در خوابكاه } \\
\hline$F V / l$ & $1 \mathrm{FF}$ & بله & \\
\hline$\Lambda N / r$ & TV. & مجرد & \multirow{2}{*}{ وضعيت تأهل } \\
\hline $11 / 1$ & re & متأهل & \\
\hline$\Delta \Lambda / \Delta$ & 189 & كارشناسى & \multirow{2}{*}{ مقطع تحصيلى } \\
\hline$f \mid / \Delta$ & ITV & دكترى حرفهاى & \\
\hline
\end{tabular}


جدول r: بررسى رابطه ميان متغيرهاى زمينهاى تحصيلى و خودكارآمدى تحصيلى

\begin{tabular}{|c|c|c|c|c|c|}
\hline معنادارى & آماره آزمون & انحراف معيار & ميانتين & & متغير \\
\hline \multirow{2}{*}{.1 .95} & \multirow{2}{*}{ I/AVI } & V/VT & $\Delta r / \wedge \Delta$ & خير & \multirow{2}{*}{ سكونت در خوابخاه } \\
\hline & & $9 / 90$ & $\Delta T / T V$ & بله & \\
\hline \multirow{2}{*}{. } & \multirow{2}{*}{$-1 / T V \cdot$} & V/TT & $\Delta r / \wedge q$ & مجرد & \multirow{2}{*}{ وضعيت تأهل } \\
\hline & & N/GT & $\Delta F / q q$ & متأهل & \\
\hline \multirow{2}{*}{$\cdot / \cdot r$} & \multirow{2}{*}{$-r / \tau .}$. & V/Vq & $\Delta 1 / 9 \Lambda$ & كارشناسى & \multirow{2}{*}{ مقطع تحصيلى } \\
\hline & & GIDT & $\Delta F / q q$ & دكترى حرفهاى & \\
\hline \multirow{2}{*}{.1799} & \multirow{2}{*}{$1 / 1 \cdot 9$} & $V / \% q$ & $\Delta r / V \Lambda$ & مرد & \multirow{2}{*}{ جنس } \\
\hline & & $V / \mathcal{R}$. & $\Delta r / V q$ & زن & \\
\hline
\end{tabular}

جدول سا: تحليل ركرسيون خطى تأثير متغيرهاى زمينهاى و تحصيلى بر خود كار آمدى تحصيلى

\begin{tabular}{|c|c|c|c|}
\hline $\mathbf{R}^{2}$ & معنادارى & بتاى استاندارد شده & متغير هاى مستقل \\
\hline \multirow[t]{5}{*}{$\cdot / \cdot \wedge \Lambda$} & $\cdot 1 \cdot \theta$ & . & سن \\
\hline & $\cdot / \cdot \Delta F$ & $-\cdot / 11 \pi$ & جنس \\
\hline & $\cdot / \cdot \Delta$ & .1190 & وضعيت تأهل \\
\hline & . & $-\cdot / I M F$ & سكونت در خوابكاه \\
\hline & $\cdot 1 \cdot \theta$ & $.119 \mathrm{~V}$ & مقطع تحصيلى \\
\hline
\end{tabular}

يكى از موضوعات مورد تأكيد در اين حيطه باورهاى مربـوط بــهـ

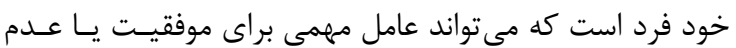

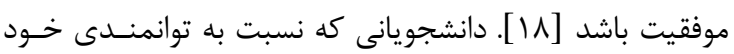

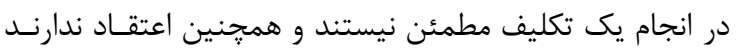

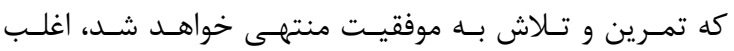

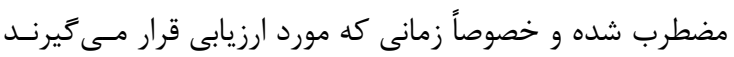
احساس عدم شايستكى مى كنند؛ در عوض دانشجويانى كـهـ بــهـ

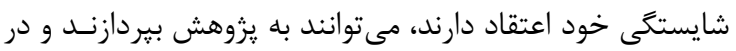

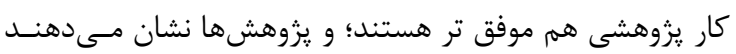

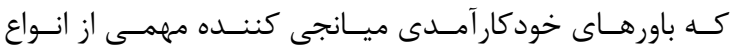

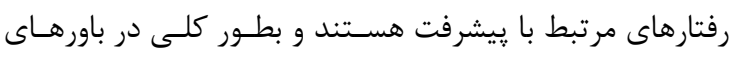

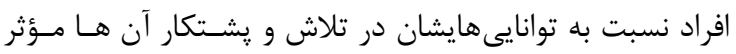

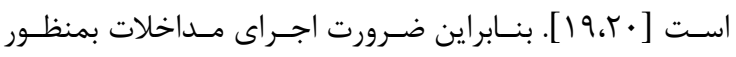

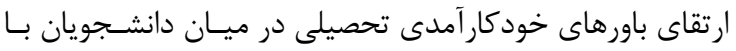

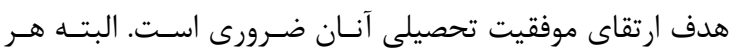
جند مطالعات متعددى نشان دهنده اثرات مثبت خود كار آمـدى آندي

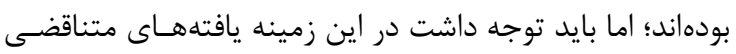

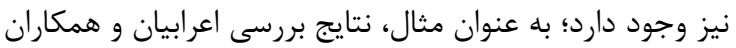

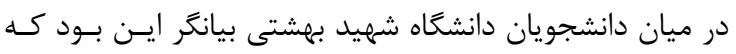

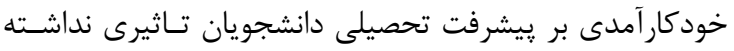

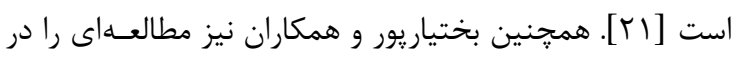

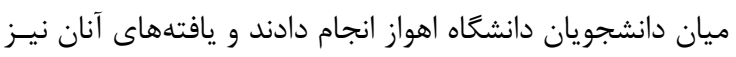

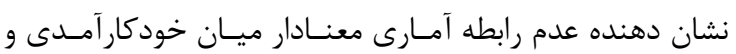

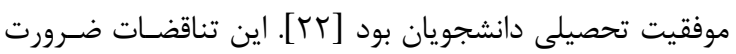

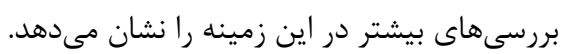

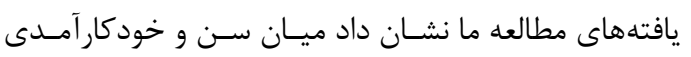

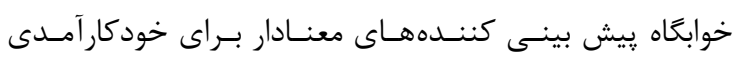

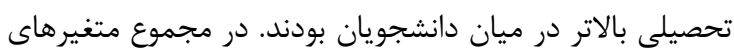

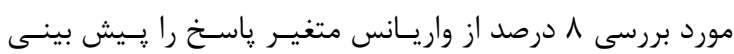
كردند. - n مورد بر

بحث

با توجه به يافته ها ميـانگين نمـره خودكارآمـدى تحصـيلى

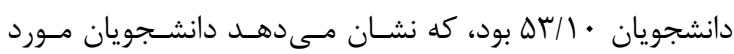

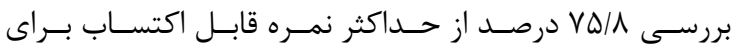
خودكار آمــدى تحصـيلى را دريافـت كردنــــ در ايــن راســـا

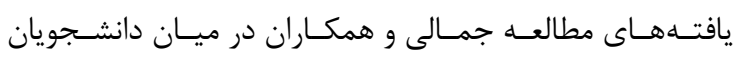

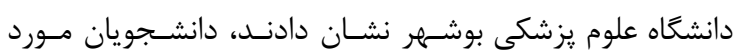

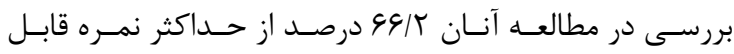

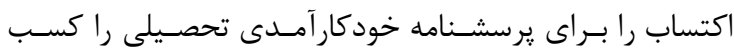

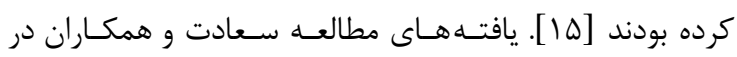

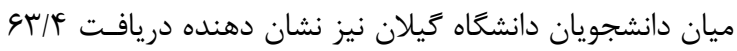

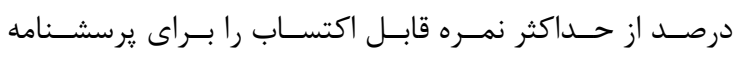

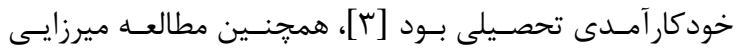

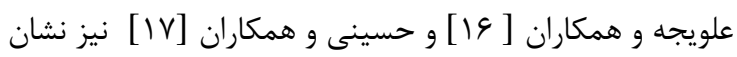

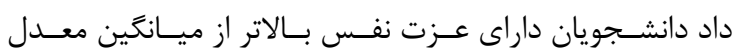

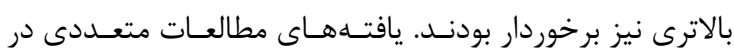

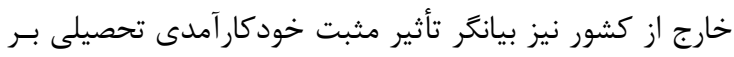

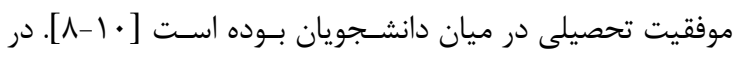

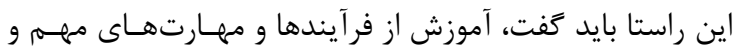

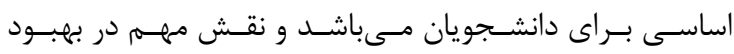
فر آيندهاى آموزشى و كسترش خدمات علمى در جامعسه دارد و 
مىرسد معنادارى حاصل از روش تحليل رگرسيون خطى بخاطر بررسى همزمان اثرات متغيرهاى ديخـر در مطالعـهـ (بــهـ عنـوان

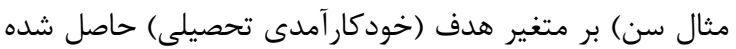

مطالعه حاضر داراى محدوديتهاى نيز بود كه از ايسن بـين

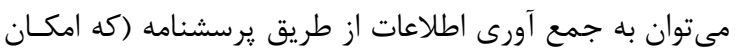

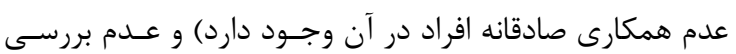
دانشجويان در رشته هاى غير يزشكى اشاره كردان

\section{نتيجه كيرى}

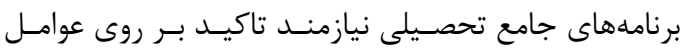

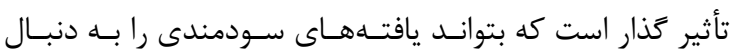

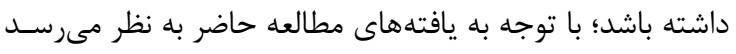

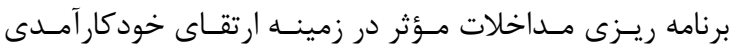

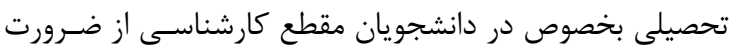

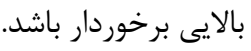

\section{تشك و قاروانى}

اين مقاله با حمايت گروه بهداشت عمومى دانشكده

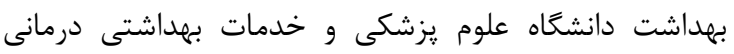
كرمانشاه انجام شد، بدين وسيله نهايت قدردانى و تشكر از

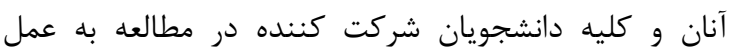
مى آيد.

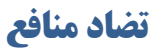

اين مطالعه براى نويسندَان هيج گَونه تضاد منافعى نداشته
تحصيلى دانشجويان مورد بررسى همبستكى مثبت و معنـادارى

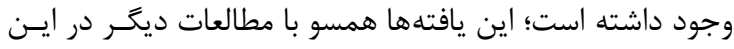

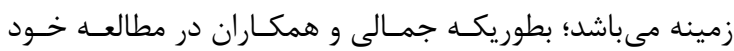

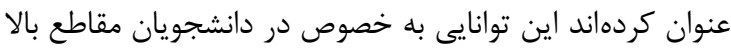

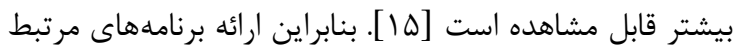

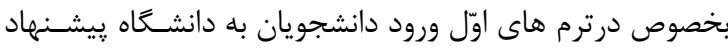
مىشود.

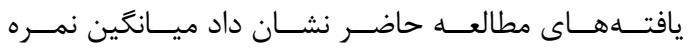
خودكار آمدى تحصيلى در ميان دانشجويان مذكر بيشتر بود امـا نـان

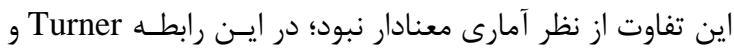

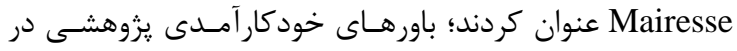

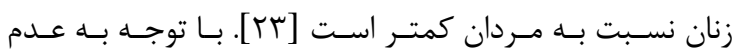

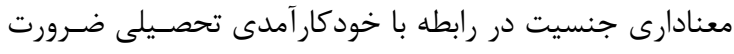

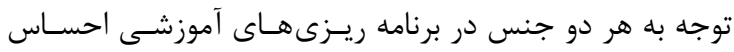

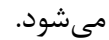

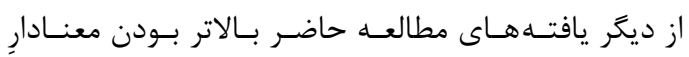

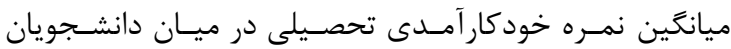

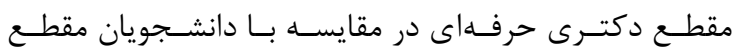

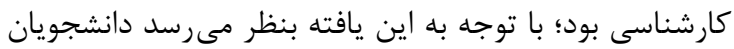

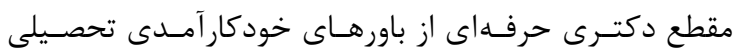
بالاترى برخوردار باشند.

نكته قابل ذكر ديخر در مطالعه حاضر اين مى باشد كهد رابطه

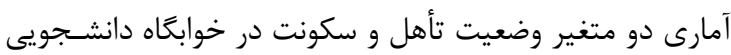
با خودكار آمدى تحصيلى بر اساس نتايج بدست آمـده از آزمــون

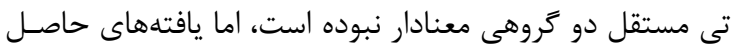

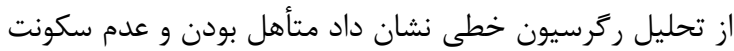

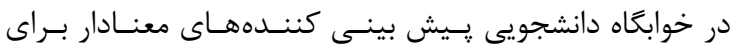

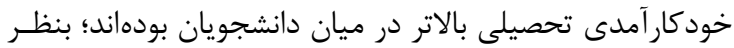

Cognitive factors related to drug abuse among a sample of Iranian male medical college students. Global journal of health science. $2015 ; 7(5): 143$. Doi: $10.5539 /$ gjhs.v7n5p143

7. Artino AR, La Rochelle JS, Durning SJ. Second-year medical students' motivational beliefs, emotions, and achievement. Med Educ. 2010: 44(12): 1203-1212. DOI: 10.1111/j.1365-2923.2010.03712.x

8. Zajacova A, Lynch SM, Espenshade TJ. Self-efficacy, Stress, and Academic Success in College. Research in Higher Education.2005; 46(6): 677-706. DOI: 10.1007/s11162-004-4139-z

9. Linnenbrink EA, Pintrich PR. The Role of Self-Efficacy Beliefs Instudent Engagement and Learning Intheclassroom. Reading \&Writing Quarterly. 2003; 19(2):119-37. http://dx.doi.org/10.1080/10573560308223

10. Chemers MM, Hu LT, Garcia BF. Academic self-efficacy and first year college student performance and adjustment. Journal of Educational psychology. 2001; 93(1):55. http://dx.doi.org/10.1037/0022-0663.93.1.55

11. Bandura A. Self-efficacy: toward a unifying theory of behavioral change. Psychol Rev 1977; 84(2):191-215. http://dx.doi.org/10.1037/0033-295X.84.2.191

12. Torres JB, Solberg S. Role of self-efficacy, stress, social integration, and family support in latino college student persistence and health. Journal of Vocational Behavior. 2001; 59(1):53-63. https://doi.org/10.1006/jvbe.2000.1785 
13. McIlroy D, Bunting B. Personality, behavior, and academic achievement: Principles for educators to inculcate and students to model. Contemporary Educational Psychology. 2002; 27(2):326-37. Doi. 10.1006/ceps.2001.1086

14. Pallant J. SPSS survival manual. McGraw-Hill Education (UK); 2013 May 1

15. Jamali M, Noroozi A, Tahmasebi R. Factors affecting academic self-efficacy and its association with academic achievment among students of Bushehr university medical sciences 2012-13. Iranian Journal of Medical Education. 2013; 13(8):629-41. (Persian)

16. Mirzaei-Alavijeh M, Rajaei N, Rezaei F, Hasanpoor S, Pirouzeh R, Babaei Borzabadi M. Comparison of selfesteem, locus of control and their relationship with university students' educational status at Shahid Sadoughi University of Medical Sciences- Yazd. Journal of Medical Education and Development. 2012; 7(1): 5870 (Persian)

17. Hosseini SN, Mirzaei-Alavijeh M, Matin BK, Hamzeh B, Ashtarian H, Jalilian F. Locus of Control or Self-Esteem; Which One is the Best Predictor of Academic Achievement in Iranian College Students. Iranian journal of psychiatry and behavioral sciences. 2016; 10(1): e2602. Doi: 10.17795/ijpbs-2602

18. Lev EL, Kolassa J, Bakken LL. Faculty mentors' and students' perceptions of students' research selfefficacy. Nurse Educ Today. 2010; 30(2): 169-74. https://doi.org/ 10.1016/j.nedt.2009.07.007

19. Garavand H, Kareshki H, Ahanchian M. The Relationship between Self-efficacy in Research and Research Performance A study on Students of Medical Sciences University of Mashhad. Iranian Journal of Medical Education. 2014; 14(1):41-51. (Persian)

20. Pajares F. Current directions in self-efficacy research. Advances in motivation and achievement. 1997; 10(149): $1-49$.

21. Arabian A, Khoda Panahi MK, Heydari M, Saleh Sedghpoor B. Relationship between self efficacy beliefs, mental health and academic achievement in colleagues. Journal of Psychology. 2005; 8(4): 360-371. (Persian)

22. Bakhtiarpoor S, Hafezi F, Behzadi sheni F. The relationship among locus of control, perfectionionism and self-efficacy with test anxiety and academic performance in the students of the Islamic Azad University. New Findings in Psychology. 2010; 5(13): 35-52. (Persian)

23. Turner L, Mairesse J. Individual productivity differences in scientific research: An econometric study of the publications of French physicists. (2003) Available at: http://citeseerx.ist. psu.edu/viewdoc/summary?doi=10.1.1.201.9136 